\title{
La apertura de China y Japón en el siglo XIX $X^{1}$
}

DOI: $10.32870 /$ mycp.v7i21.217

Melba E. Falck Reyes*

J apón ocupa hoy un lugar privilegiado en el mundo. Es la segunda economía más poderosa y su participación en los flujos internacionales de bienes la colocan en un tercer lugar. Las mercancías hechas en Japón inundan los mercados internacionales, distinguiéndose por ser productos de alto valor tecnológico y de calidad. Los procesos de producción empleados en dicho país son hoy emulados en muchos países. Los excedentes de capital japonés, obtenidos del intercambio de bienes con otros países, son destinados a proyectos de inversión en la mayoría de los países del mundo. Además, Japón se ha convertido hoy en el mayor donador de ayuda a los países en desarrollo.

Este status de nación industrializada fue alcanzado por Japón en un corto período de 50 años. A partir de la llegada del comodoro Perry a costas japonesas, Japón pasó de ser una nación sometida a "tratados desiguales" por los poderes imperialistas de occidente, a ser una nación soberana reconocida por la comunidad internacional.

La modernización de Japón se inició en el período de Meiji, 1868-1912. Durante ese lapso los líderes de Meiji se propusieron alcanzar el status de las naciones occidentales desarrolladas y para tal fin enviaron misiones de estudio a occidente para que "al estudiar $\mathrm{su}$ fortaleza y su mejor manera de hacer las cosas, podamos (los japoneses) ser más fuertes [...] Trabajaremos para poner a Japón sobre bases iguales, en el futuro, con aquellos países cuya civilización moderna es ahora nuestra guía". ${ }^{2}$ Así se expresaba Ito Hirobumi, líder de Meiji, cuando visitó Estados Unidos como miembro de la misión Iwakura, en 1872.
China, con una quinta parte de la población mundial, es hoy un actor clave en el sistema internacional. China llevó a cabo una política de "puertas abiertas", a partir de las reformas iniciadas en 1979 por Deng Xiaoping y ocupa actualmente el undécimo lugar como nación exportadora; recientemente, ingresó a la Organización Mundial de Comercio (oMc).

Esta clara tendencia a la apertura exterior no es un fenómeno nuevo en China, aunque sus características sí lo son. En el siglo XIX, cuando la revolución industrial lanzó los poderes occidentales a la conquista de los mercados portugueses, ingleses, franceses y alemanes, establecieron sus "zonas de influencia" en el este y sudeste de Asia. China quedó repartida así entre los principales poderes de la época. El "siglo de los tratados desiguales" en China finalizó con el ingreso del Partido Comunista en 1949.

La apertura forzada al exterior por parte de los poderes occidentales es compartida tanto por Japón como por China en el siglo XIX. A la llegada de los occidentales, ambos países habían estado aislados del mundo exterior y fueron sometidos a los "tratados desiguales de extraterritorialidad" bajo la amenaza de las "cañoneras". Sin embargo, la respuesta a la invasión occidental fue diferente en los dos países. A Japón le tomó medio siglo alcanzar el status de nación soberana. China tendría que esperar otro tanto para "ponerse de pie". ${ }^{3}$

¿Cuáles fueron las razones que llevaron a estas dos naciones asiáticas a un resultado tan diferente? ¿Por qué a Japón le tomó mucho menos tiempo que a China convertirse en un estado moderno? Responder a las preguntas es el objetivo de este ensayo.

* Profesora investigadora del Departamento de Estudios del Pacífico, de la Universidad de Guadalajara.

ORCID http://orcid.org/0000-0003-4926-0594 


\section{El entorno internacional}

En el siglo XIX la fortaleza europea se vio reforzada por la revolución industrial que le proporcionó mayores ventajas en su poderío marítimo, el cual ya había introducido el comercio global en todas partes del mundo. ${ }^{4} \mathrm{El}$ desarrollo de los ferrocarriles y de los barcos a vapor trajeron consigo menores costos de transporte, que acompañados con reducciones a las barreras del comercio, propiciaron un espectacular crecimiento del comercio internacional. En el siglo XIX el comercio se vio impulsado por la creación de varias uniones aduaneras y tratados de libre comercio. Entre los acuerdos bilaterales de la época sobresalen el anglofrancés de 1860, que incluía la cláusula de Nación Más Favorecida (NMF). A principios de siglo, Gran Bretaña había suscrito tratados con 46 estados, Alemania con $30 \mathrm{y}$ Francia con más de veinte. ${ }^{5}$

El comercio se convirtió en el medio de la expansión política de los poderes occidentales y la riqueza que el comercio generaba hizo que éste empezara a influir más directamente sobre los aspectos políticos. Ello constituyó el mayor desafío para las élites feudales de Asia. ${ }^{6}$ En 1800 el comercio con China había crecido sobre todo en té y seda. En los siguientes cincuenta años este comercio constituyó la forma de penetración en Asia y luego la razón de las relaciones institucionales basadas en el llamado "sistema de tratados" de puerto que se extendería a todos los vecinos de China. ${ }^{7}$

En la década de los ochenta del siglo XIX, las relaciones internacionales entraron en una fase de expansión colonialista. El mundo internacional estaba dominado por los poderes occidentales. El imperialismo comercial de la época se caracterizaba, en primer lugar, por la prioridad otorgada al acceso a los mercados utilizando la cláusula de $\mathrm{NMF}^{8} \mathrm{y}$, en segundo lugar, por la gran importancia que dieron los poderes a China como modelo para seguir en otros países. En este contexto internacional se da la invasión occidental a China, Japón y al resto de Asia en el siglo XIX.

\section{China en el siglo XIX}

Los "bárbaros del norte" volvieron a conquistar China. Esta vez fueron los manchúes que introdujeron una burocracia $\mathrm{y}$ un gobierno bilingüe $\mathrm{y}$ birracial con un control militar fuerte sobre China y fundaron la dinastía Qing (1644-1911). La historia de China del siglo XIX se caracterizó por las rebeliones frecuentes, las invasiones extranjeras y el esfuerzo de la élite gobernante por controlar ambas y mantenerse en el poder. De acuerdo con Fairbank, los historiadores actuales ponen mayor atención al impacto del imperialismo extranjero en la desorganización social y la desmoralización psicológica en la sociedad china. Sin embargo, los problemas de la China del siglo XIX comenzaron con las rebeliones al interior del país. $^{9}$

Seis rebeliones azotaron el país ese siglo. La rebelión del Loto Blanco, de 1796 a 1804, que fue impulsada por una secta religiosa rural y antimanchú, que luchaba contra la pobreza imperante en el campo. La rebelión de Taiping, de 1851 a 1864, se originó en el sur, entre Cantón y el Interior, 
en una región con mayor contacto con el exterior sobre la cual los Qing tenían menor control y que a la vez poseía un gobierno local débil. El control era más bien ejercido por los terratenientes que luchaban entre sí. La debilidad del gobierno manchú, puesta al desnudo por la agresión de occidente, abrió los ojos a las sociedades patrióticas. Así surgió el movimiento Taiping, dirigido por un cristiano protestante, el cual se caracterizó por una amalgama de ideas orientales y occidentales encaminadas hacia la acción militar. Durante esta guerra se conquistaron 600 ciudades amuralladas y la capital "celestial" se estableció en Nanking, dejándole Shanghai a los extranjeros. Otras rebeliones que afectaron China en esa época fueron la de los musulmanes chinos del sudoeste y la del noroeste, entre 1855 y 1873, así como la Rebelión de los Bóxers entre 1898 y 1901, que se desarrolló al norte en Shandong. Este último fue un movimiento campesino que tuvo como lema "apoyar a los Qing y destruir a los extranjeros". Cada uno de estos movimientos debilitó al gobierno Qing. En este entorno de inestabilidad interna se dio la invasión extranjera occidental.

\section{La apertura forzada de China}

El denominado "siglo de los tratados", bajo los cuales le impusieron a China una apertura forzada, puede dividirse en tres fases de acuerdo con el papel desempeñado por los extranjeros: de 1842 a 1870 , la fase de imperialismo de "libre comercio" de los británicos; $;^{10}$ de 1870 a 1905, la rivalidad de las potencias extranjeras en China; de 1900 a 1940, la invasión del territorio Chino por parte de Francia, Inglaterra, Japón y Alemania.

Inglaterra inicialmente utilizó a "los comerciantes chinos de ultramar" para llevar a cabo su comercio con China. El denominado "sistema cantonés" era la base de las relaciones comerciales entre los dos países, las cuales estaban confinadas al puerto de Cantón. El gobierno encargaba a un grupo de empresas familiares chinas, cuya asociación era denominada Cohong, para que actuaran como intermediarias en el comercio con los extranjeros.
El Cohong era supervisado por un funcionario manchú de la casa imperial de la Corte Interior de Pekín, que era conocido como el Hoppo. Tanto este último como el Cohong se encargaban de la recolección de los impuestos del comercio; este privilegio sería perdido por China en las siguientes décadas de dominación extranjera. La compañía británica de las Indias Orientales que tenía el monopolio del comercio, se adhirió al "sistema cantonés" y funcionó de común acuerdo hasta 1834 , cuando perdió el monopolio real del comercio.

Bajo este sistema la dinastía Qing mantenía un control fuerte sobre el comercio restringiendo las actividades de los comerciantes extranjeros tanto al sur como al norte. Así, los poderes occidentales fueron rechazados cuando trataron de obtener mayores ventajas para el comercio y derechos de residencia diplomática en Pekín. Ello sucedió en 1793, cuando la Cía. de las Indias Orientales envió una misión diplomática a China en un buque con " 66 cañones" para solicitar mayores oportunidades de comercio y representación diplomática en $\mathrm{Pe}$ kín. Ésta fue rechazada por los chinos. Igual suerte tuvo otra embajada británica en 1816 . Sin embargo, para ese entonces tanto Gran Bretaña como la India Británica desempeñaban una función clave en la apertura de China al comercio exterior. Pero la corte Qing no estaba interesada en la "China marítima" y no se imaginaba al mundo exterior con el cual tendría que tratar más adelante, su preocupación era controlar tanto el interior como las fronteras marítimas y terrestres de China. El control político y el ejercicio de la autoridad central fue la preocupación de todas las dinastías anteriores y de los gobiernos chinos posteriores.

El comercio entre China e Inglaterra se centraba en ese entonces en las exportaciones de té, seda y porcelana procedentes de China, y las importaciones de esta última fueron plata, tejidos de lana y opio introducido desde la India. Este último país pagaba las importaciones de té de Inglaterra. Cuando en 1834 el gobierno inglés suspendió el monopolio de la Cía. de las Indias Orientales, el gobierno chino tuvo 
que enfrentarse no sólo a aquél sino al mal social introducido por el consumo ilegal del opio. El intento del gobierno manchú por controlar este último dio origen a la Guerra del Opio, entre 1839 y 1842 , que más bien fue una guerra para asegurar los privilegios de las relaciones comerciales y diplomáticas sobre una base de "igualdad" occidental.

Con la victoria de Gran Bretaña se firmó el tratado de Nanking en agosto de 1842, que incluía las siguientes condiciones: extraterritorialidad que concedía la jurisdicción del país extranjero sobre sus súbditos; aranceles moderados y contacto directo de los extranjeros con los aduaneros; trato de NMF; libertad para comerciar con todos los interesados y una indemnización. ${ }^{11} \mathrm{Y}$ por sobre todo eso, Inglaterra obtuvo a Hong Kong y la apertura de cinco puertos: Shanghai, Ningbo, Fuzhou, Amoy y Cantón.

Los puertos abiertos constaban de una zona, el bund, de muelles y bodegas llenas de culis - trabajadores chinos-y un jefe de personal nativo, el comprador, que manejaba los asuntos bajo el dominio absoluto de los taipan extranjeros. Cada puerto tenía un enclave extranjero y era protegido por una flota de cañoneras ancladas frente al bund.

En 1856 estalló otra guerra cuya razón de fondo era que los británicos no veían que su comercio, bajo los tratados existentes, floreciera como ellos esperaban. Esto lo atribuían a dos factores: falta de acceso al mercado interno de China y a que los oficiales chinos en los puertos abiertos no cumplían cabalmente con los tratados. La victoria de Gran Bretaña, aliada con Francia, culminó en el tratado de Tientsin (1858), que abrió a los extranjeros más puertos sobre el Yangtzé y en el norte, así como el derecho de abrir una legación en Pekín. ${ }^{12}$

Los bajos aranceles acordados no lograron proteger la industria china. Al final los extranjeros se encargaron de la administración de los aranceles y fueron "guardianes de una competencia leal". El comercio internacional se desarrolló bajo estas condiciones y al ha- cerlo proporcionó ingresos importantes tanto a las zonas costeras como a Pekín. Después de la década de los ochenta las importaciones de opio provenientes de la India disminuyeron, pues éste ya se producía en China. China terminó firmando tratados desiguales con Estados Unidos y Francia en 1844, y con Inglaterra, Francia, Estados Unidos y Rusia en 1858. En 1860 se dio la ocupación anglofrancesa de Pekín, que consolidó la aceptación del antiguo sistema de tratados.

A partir de 1860 comenzó una alianza entre los británicos y los Qing. Los primeros buscaban estabilidad en el comercio con Pekín y se convirtieron en los administradores del servicio de aduanas en calidad de funcionarios de los Qing. Ello les permitió participar en la política nacional de China.

En 1862 un golpe de Estado aseguró el poder a la emperatriz viuda y dos manchúes. El nuevo gobierno decidió llevar a cabo una política dual: en el plano externo la aceptación de los tratados con el objeto de apaciguar a las potencias extranjeras y en el plano interno, asignar cargos de poder a ciudadanos chinos con el fin de derrocar a los rebeldes de Taiping. Bajo la dirección del erudito Zeng Guofang, se inició un proceso de modernización, la Restauración Qing (1861-1876), en el cual se pusieron a funcionar nuevamente los componentes de un estado confuciano y a la vez se impulsó la occidentalización.

La restauración perdió vitalidad, ya que los líderes revivían el pasado y no lograban motivar de forma adecuada a la burocracia. Se mostraron incapaces de manejar los problemas específicos que planteaba la occidentalización. Este esfuerzo conservador y restaurador impidió que China respondiera al contacto occidental de forma revolucionaria. Así, a mediados de siglo los trastornos sociales más importantes en China fueron causados por las rebeliones internas; mientras tanto, los privilegios especiales concedidos a los poderes occidentales en los puertos abiertos, constituían la periferia de ese gran trastorno social. ${ }^{13}$ 
Posterior a la restauración en China, se postulaba como política "el saber chino como estructura fundamental y el saber occidental para los usos prácticos". ${ }^{14}$ Así, la generación de 1860 a 1900 se mantuvo fiel a la consigna de que China podía saltar a los tiempos modernos. Basados en la postura clásica de autorreforzamiento, los líderes chinos empezaron a adoptar armas y máquinas occidentales. Lo que el gobierno central no entendía es que al final ello implicaría la adopción de la tecnología, la ciencia, la enseñanza en general, las nuevas ideas, nuevas instituciones y finalmente una revolución republicana. La falacia de una occidentalización a medias en los instrumentos pero no en los valores, fue reconocida por muchos eruditos chinos.

En 1894 y 1895 China se enfrentó a los japoneses. Los chinos estaban mal preparados: los fondos para construir una flota de guerra habían sido desviados para la reconstrucción del palacio de verano de la emperatriz, que había sido incendiado en la guerra de 1860. La dinastía Qing había logrado sobrevivir a las rebeliones pero las relaciones internacionales se le escapaban de las manos. El resultado de la guerra sino-japonesa fue una década de rivalidades imperiales en Asia del este. Pero no sólo eran los intereses comerciales los que sometían a China, los religiosos también tuvieron parte en esa dominación. Entre 1860 y 1900 se dio la expansión gradual de los misioneros amparados en el derecho de extraterritorialidad.

En 1898 los poderes extranjeros exigieron cada uno sus "zonas de influencia”. Rusia, Alemania, Gran Bretaña, Japón y Francia mantenían sus respectivas zonas, las cuales incluían una extensión de territorio, un puerto con su respectiva flota naval, un ferrocarril y minas para su explotación. Ese fue el año en que inició la Rebelión de los Bóxers y los extranjeros utilizaron ese pretexto para atacar las costas chinas. En 1901 se firmó el Protocolo de Pekín con once potencias extranjeras, que entre otras cosas demandaba una indemnización por 333 millones de dólares a tasas de interés que duplicaban el monto adeudado mientras se exigía que el Distrito de las Legaciones extranjeras de Pekín fuera ampliado y provisto de guarniciones militares armadas al igual que el ferrocarril. Después de su derrota, la dinastía Qing duró en el poder diez años más. Pero en ese tiempo se fue debilitando cada vez más mientras se ampliaba la brecha entre la China urbana y moderna de los puertos abiertos y la China interior de numerosos poblados.

Durante esos años se dieron también muchos cambios de manera vertiginosa: en el vestir, en las campañas contra el opio y el vendaje de los pies, circulación de periódicos y revistas y el correo, trayendo consigo nuevos patrones de organización económica y nuevas ideas de cómo gobernar el país. En los puertos abiertos surgieron nuevas profesiones. Sin embargo, es necesario hacer notar que el cambio no era una incursión puramente occidental, por el contrario, cada nueva idea occidental se desarrolló sobre una institución o concepto chino: las estructuras bancarias chinas se ajustaron a las occidentales; los sistemas de distribución chinos eran utilizados para mover los productos innovadores occidentales y las asociaciones nativas de comercio se convirtieron en cámaras de comercio. Los grupos de discusión en las aldeas darían a paso a las asambleas locales. ${ }^{15}$

La dinastía Qing no pudo contener ni coordinar estos cambios, ni digerir sus implicaciones. Los manchúes trataron de establecer el control militar y de introducir el cambio constitucional desde arriba y se vieron debilitados por la invasión japonesa y las rebeliones internas. Finalmente, en 1911, por una disputa sobre el control del ferrocarril en Sichuan, se dio una revuelta que concluyó con la declaración de independencia de las provincias del régimen Qing. La Liga Revolucionaria fundó la República China en 1912 en Nankín, con Sun Yatsen como presidente, terminando así dos mil años de poder imperial en China. 


\section{Japón a la llegada de los extranjeros}

En 1603 se estableció el Shogunato en Japón con un gobierno centralizado (el Bakufu, gobierno central) con base en Edo (Tokio). Durante el período Tokugawa, 1603-1868, se mantuvo un orden social estable por 264 años, con tres clases diferenciadas: la gobernante $o$ dominante que incluía al Shogun, los daimios y los guerreros comunes o samurai; la clase dominada que comprendía a los agricultores, los artesanos y los comerciantes; la clase noble, alejada, compuesta por la familia imperial y los nobles civiles. ${ }^{16}$ En esa época se desarrolló un sistema administrativo y legal eficiente. En el siglo XVII se dobló la productividad del arroz y los cultivos comerciales se extendieron a lo largo del país. Con el desarrollo de varias industrias prosperaron muchas ciudades y la clase mercantil (chônin) superó a la samurai. ${ }^{17}$

En 1630 el gobierno prohibió el cristianismo, la entrada de barcos portugueses a Japón y los viajes de los japoneses al extranjero. El shogunato advertía una intención de conquista política por parte de los misioneros y, por lo tanto, adoptó una política de aislamiento, llamada Sakoku. Con todo, Holanda y China continuaron comerciando en el puerto de Nagasaki y se siguió infiltrando alguna información del mundo exterior. Hacia finales del siglo XVIII, los científicos comenzaron a estudiar ciencias occidentales como la medicina y la astronomía utilizando el idioma holandés.

En la segunda mitad del siglo XVIII, el tráfico de mercaderías experimentó un ulterior desarrollo tanto en las áreas urbanas como rurales. Como resultado, el Shogunato y los daimios (señores feudales) encontraron que los ingresos provenientes de los impuestos al arroz disminuían y se incrementaron los tributos, lo que condujo a un descontento social. Aumentaron las diferencias de ingreso entre los ricos chônin y los daimios por un lado, y los campesinos por el otro, lo que condujo a enfrentamientos entre ellos. Surgió entonces el deseo de una reforma política. En ese entorno llegaron los extranjeros a Japón.
Japón también es obligado a abrirse

Tanto para los rusos como para Inglaterra, Japón era un área geográfica que estaba en el perímetro de sus áreas de influencia: la región del norte y este de Manchuria y China. Al llegar Perry surgieron dos posturas encontradas en Japón: una, la de modernizar Japón militarmente adquiriendo el conocimiento de los avances occidentales y la otra, la de continuar con la política deSakoku, utilizando las armas. Mientras tanto, Estados Unidos vio a Japón como un factor importante en sus relaciones con China. Esto fue todavía más claro cuando Estados Unidos estableció autoridad formal sobre Oregon y California. Japón fue visto como un punto intermedio en la ruta a China, no sólo por su capacidad de proveer de carbón a los buques que hicieran escala en las cercanías de Nagasaki, sino porque estaba en la ruta entre Shanghai y San Francisco.

Así, con el impulso de la guerra del opio en China, se consideró más fácil entrar a Japón y en 1853 el comodoro Mathew C. Perry arribó a la Bahía de Tokio con sus buques "negros". La experiencia China de apertura bajo el "sistema de tratados" desiguales fue de una importancia crítica para Japón. Sin embargo, la respuesta japonesa no iba a ser copia fiel de la de China, ya que la posición interna y externa de Japón era diferente $y$, por lo tanto, este país entraría al sistema de tratados de una manera distinta. En primer lugar, la apertura de Japón la llevó a cabo Estados Unidos y no Gran Bretaña, ya que para esta última Japón no era tan importante como Cantón. China comerciaba con Japón directamente en el puerto de Nagasaki e indirectamente en el sudeste asiático a través de la Cía. Británica de las Indias Orientales. Esta última no realizó esfuerzos serios para abrir Japón, ya que éste no ofrecía productos que interesaran en Europa, excepto cobre para los mercados asiáticos; los japoneses por su parte demandaban exclusivamente productos orientales. Esto dejó libre el camino a los norteamericanos. Por otra parte, la situación política en Japón era diferente a la de China y por lo tanto la política apropiada para uno no lo era para el otro. 
En 1854 Estados Unidos firmó un tratado con Japón, más enfocado a obtener facilidades para el comercio, que abría los puertos de Shimoda y Hakodate; designaba un cónsul americano en Shimoda; incluía una cláusula de NMF y el derecho a comprar bienes en los puertos abiertos. Inglaterra y Rusia firmaron convenios bajo el modelo de Perry en 1854 y 1855, respectivamente. Con Rusia se dividieron las islas Kuriles entre los dos países, aunque no se definieron las fronteras con la isla Sakhalin. Además de los dos puertos mencionados, se abrió Nagasaki.

En 1858 Japón firmó tratados con Estados Unidos, Rusia, Holanda, Gran Bretaña y Francia sobre la base del modelo estadounidense. La apertura de los puertos modificó el papel de los poderes occidentales en Japón. Rusia y Estados Unidos se replegaron, al obtener el primero las islas del norte y el segundo por razones internas relacionadas con la guerra civil norteamericana. Inglaterra, con su flota y su dominio del comercio en Asia, adquirió entonces poder de veto en la política con respecto a Japón, mientras este último obtuvo mayor importancia por sus exportaciones de seda. Japón iba perdiendo sus propios distintivos en las relaciones internacionales, siendo absorbido por un patrón más amplio centrado en China. ${ }^{18}$

Los tratados tuvieron efectos económicos importantes en la sociedad japonesa que permitirían luego atribuir a los extranjeros las crisis económicas por las que atravesaba el país. Estos efectos tendrían consecuencias sobre el tipo de cambio y sobre los gastos de defensa del gobierno. ${ }^{19}$

Ante la amenaza externa, el Bakufu y los daimios gastaban cada vez más en tecnología y armas occidentales. Después de 1863, las demandas occidentales por indemnización se fueron elevando y ello ponía más presión sobre los ingresos feudales, causando más inflación. Esta última era entonces culpa de los "tratados desiguales".
La política externa del Bakufu era vista con recelo tanto por los samurai como por los señores feudales. Los primeros percibían no sólo una amenaza a la cultura y al orden social y político, sino al territorio y a la nación; para los segundos era el temor de que la invasión extranjera podía socavar el orden interno. Ambas clases trataron de influir sobre la política externa para dar marcha atrás en los tratados. Surgió así el lema "honrar al emperador, expulsar a los bárbaros". Y aunque el Bakufu reconocía la debilidad de Japón al tratar con occidente, en las esferas más alejadas del centro había un menor reconocimiento de esta situación.

Los samurai deseaban transferir el poder al emperador y sus asociados feudales y los daimyô, por su parte, deseaban más independencia del centro. Ambas posturas eran una amenaza al Bakufu. Esto trajo una división en los Consejos de Edo, la capital de Bakufu que después se llamaría Tokio: un bando consideraba que la mayor amenaza provenía del poder extranjero y, por lo tanto, había que controlar la oposición interna para evitar una guerra desastrosa; mientras tanto, la otra facción veía la necesidad de entablar acuerdos con la oposición y establecer la unidad nacional, lo cual proveería las bases para un acuerdo sobre la política exterior. Esto suponía en el corto plazo, aceptar los tratados. Hasta que estas diferencias no se resolvieran, Japón no podría tener una relación estable con el exterior. Mientras tanto, Kioto ponía presión sobre el Bakufu para expulsar a los extranjeros.

Un incidente en los estrechos de Shimonoseki, en el cual un daimios de Chôsh $\hat{u}$ atacó buques norteamericanos, franceses y holandeses, sería el factor que haría definir la política externa. Finalmente, fueron cerrados los estrechos de Shimonoseki, lo que ocasionó que en 1864, 17 buques extranjeros se dirigieran a Shimonoseki para concluir con la firma de un tratado entre los poderes occidentales y el Bakufu. Este tratado imponía una indemnización de 3 millones de dólares mexicanos, pues se convinieron en plata mexicana amonedada de circulación entonces en Japón, 
o la apertura de Shimonoseki u otro puerto como pago. Este ataque convenció a los señores feudales de su inferioridad militar y a sus sucesores les serviría para establecer una política sobre cuál sería la mejor forma de manejar los tratados desiguales. Finalmente, fue emergiendo un consenso de que había que adoptar las técnicas de occidente para construir la fortaleza de Japón. El emperador dio su consentimiento a los tratados y el Bakufu se comprometió a abrir los puertos.

En 1866 se firmó una convención con los cuatro poderes occidentales mediante la cual se establecía un arancel muy bajo a las exportaciones e importaciones de 5 por ciento; se prohibía la importación de opio y las exportaciones de arroz, trigo y cebada. El comercio de oro, plata y cobre quedaba bajo el control del gobierno. Los japoneses tenían libertad de comprar diseños de barcos y descripciones de navegación; los comerciantes japoneses quedaban en libertad de comerciar no sólo en los puertos abiertos, sino en cualquier lugar del extranjero y todos los japoneses podían viajar al exterior por razones de estudio o negocios. Esta convención arancelaria completó la apertura de Japón al comercio.

En 1868 estalló la guerra civil, se destituyó al shogun y se restauró al emperador en el poder, con lo que se inició la Restauración Meiji. Los daimios más poderosos de Japón solicitaron al emperador una política fresca en asuntos externos para evitar "el mal ejemplo de China". ${ }^{20}$

\section{La política exterior durante la Restauración Meiji}

El renacimiento japonés fue distinto al chino. En China éste tuvo su origen en el deseo de liberalizar a la sociedad. En Japón, la fuerza motriz no fue el liberalismo sino la reacción. "Lo que Japón buscó no fue una sociedad que extrajera su fuerza del liberalismo, sino una rápida asimilación del conocimiento y las técnicas occidentales para fortalecerse. En China el movimiento fue espontáneo y careció de una dirección planeada. En Japón, una vez que se reconoció el vínculo entre seguridad nacional y los conocimientos occidentales, el renacimiento fue planeado y puesto en práctica por el gobierno, que en ningún momento olvidó la necesidad de mantener la solidaridad nacional y el poderío militar". ${ }^{21}$

Pueden distinguirse dos períodos en la política externa de Japón en esa época: de 1868 a 1880, en el que los asuntos deben ser vistos como subsidiarios de los desarrollos internos. (era necesario consolidar el poder central e incorporar las masas a la política), y el período de 1880 a 1912 , cuando las relaciones internacionales de Japón entraron en una fase de expansión colonial.

El régimen de Meiji le dio prioridad a establecer el control sobre los asuntos externos como prerrequisito para consolidar su poder. En 1868 el gobierno imperial declaraba que "las condiciones internas son inestables, pero los asuntos externos son extremadamente importantes [...] Éstas son las tendencias de los tiempos". ${ }^{22}$

Los líderes de Meiji tuvieron éxito tanto en prevenir que los asuntos externos exacerbaran las tensiones domésticas como en usar dichos asuntos para estabilizar el orden interno. Ambos sectores se desarrollaron de manera simbiótica, y en el reconocimiento de su vínculo radicó el éxito de los líderes de Meiji. Los nuevos líderes tomaron las relaciones internacionales muy en serio: en su nueva política fueron prohibidos los ataques a extranjeros, pues estaban "contra las leyes del mundo". ${ }^{23}$

Se estableció además un nuevo sistema legal que garantizó la seguridad de todos, incluyendo a los extranjeros y, por lo tanto, la cláusula de extraterritorialidad de los tratados sería innecesaria. Al aceptar estas leyes universales, Japón podría "establecer su prestigio en el mundo", y por fin se definirían las fronteras con claridad. Fue un programa de occidentalización planificada, un sistema cuidadosamente pensado y controlado, cuyo objetivo era crear la fuerza nacional. El mismo 
emperador así lo manifestaba: “Cómo quisiera que este país no fuera inferior a ninguno, adoptando lo que es bueno y rechazando todo lo que es malo!". ${ }^{24}$

Con esos objetivos en la mira, fueron enviadas misiones a Estados Unidos e Inglaterra para aprender el funcionamiento de los sistemas políticos y las instituciones legales para que pudieran ser introducidas a Japón, y al adoptarlas recibir un trato igualitario como nación soberana. También ya se planteaba a los poderes occidentales la necesidad de revisar los tratados. Sin embargo, éstos reclamaban primero la revisión de las leyes civiles, impositivas y comerciales antes de observar los tratados. Ante esta negativa de los poderes occidentales, el gobierno vio la necesidad de formar una asamblea nacional para contar con el respaldo popular en la negociación de los tratados y a la vez ser reconocido como un estado moderno.

En 1874 Japón retiró sus residentes de la isla Sakalin y demandó a Rusia el control de las Kuriles. Un año más tarde se firmaba un tratado mediante el cual Japón era considerado como igual por un poder occidental. Ello le ganó al gobierno la aprobación popular. También en ese año, y a raíz de un incidente en que unos pescadores de las islas Ryûkyû fueron agredidos por los chinos en Taiwan, Japón dirigió una misión de castigo a Taiwan, provincia china. Japón extendió así su control sobre una región cercana a Taiwan y a China continental.

Japón y China habían firmado un acuerdo en 1871 por medio del cual se establecían relaciones diplomáticas normales entre los dos países y se garantizaba la mutua extraterritorialidad. Tres años más tarde China percibía a Japón como una amenaza, y para este último China pasaba de ser un vecino amistoso a un adversario potencial. Japón seguía así el patrón de otros estados en la delimitación de su territorio, al tiempo que redefinía sus necesidades de seguridad.
En 1875 le tocó el turno a Corea, la cual se consideraba un estado tributario de China. Japón firmó con Corea un tratado desigual en 1876 , en el que ésta le abría tres puertos y le daba jurisdicción consular. Además, Corea era reconocida como un estado independiente y no tributario de China. En los cálculos de los líderes de Meiji, el éxito en estas incursiones externas consolidaba su poder interior. Entre 1880 y 1895 Japón estableció enclaves coloniales en Corea, Taiwan y partes de China.

En los ochenta se habían alcanzado las precondiciones políticas para convertir a Japón en un Estado moderno: se había consolidado un marco político y burocrático; se establecieron las bases para una constitución y la formación de una asamblea, la Dieta Imperial; el pueblo se había educado y politizado, situación que fue canalizada hacia la cohesión nacional. Por ello, cuando los poderes occidentales lanzaron su ola colonizadora, Japón estaba mejor equipado para hacerle frente. Sus tratos con el exterior estarían apoyados por un gobierno centralizado y una opinión pública más asertiva que antes.

En 1885 la política expansionista de Japón se basaba en el deseo de consolidarse como un Estado moderno; sin embargo, era justificada en aras de emular a occidente y "dejar Asia”. ${ }^{25}$ El etnocentrismo tradicional en Japón, alimentado por el aislamiento geográfico y la homogeneidad cultural y racial, se convirtió en un patriotismo moderno.

En este contexto se desarrollaron las relaciones con Corea y China. Las relaciones con China continuaron tensas hasta que culminaron con la guerra de 1895 . Vencedor Japón, en el tratado de Shimonoseki, le fueron impuestas a China las siguientes condiciones: el reconocimiento de Corea como un estado independiente; la cesión de la península de Liaotung y Taiwan a Japón: una indemnización de 200000 taels; la apertura de cuatro puertos; la cláusula de NMF; la libre navegación en el Yang Tse y el otorgamiento a los japoneses del derecho a establecer fábricas de manufacturas en China. 
Estas demandas reflejaban "las líneas de interés" de Japón: adquisición de territorios en ultramar, igual status de los poderes occidentales en China y derechos económicos, además del pago de una indemnización que serviría para financiar el desarrollo industrial de Japón. En 1897, cuando todos los poderes occidentales reclamaban zonas de influencia en China, Japón hizo lo propio reclamando Fukien frente a Taiwan.

Mientras tanto, la industrialización de Japón seguía su curso en la industria textil del algodón y la seda, en la del hierro y el acero que se vieron impulsadas por la guerra sinojaponesa. Así, el imperialismo coincidió con la rápida industrialización. En 1875 el gobierno le regaló 30 barcos a la Compañía Iwasaki Yutarô Mitsubishi, con un subsidio anual de 200000 yenes, medida que fue tomada por razones de seguridad para eliminar las compañías de transporte internacional que dominaban el comercio en las costas. Mitsubishi se convertiría en una de las mayores empresas clave en la construcción industrial moderna y el comercio y las compañías extranjeras se retiraron.

El servicio postal inició en 1872 con 21 oficinas y en 1874 tenía más de 3000 . El gobierno adquirió las plantas de municiones, las de construcción de barcos y las empresas mineras, y continuó desarrollándolas hasta 1881. En materia económica el gobierno tenía tres prioridades: desarrollar la industria militar en vista de la amenaza extranjera, desarrollar la industria con un alto porcentaje de importaciones y crear un efecto-demostración al familiarizar a los japoneses con las técnicas de producción y administrativas y apoyar el desarrollo de la agricultura con la importación de tecnología. ${ }^{26}$

A fines del siglo XIX, el estado japonés aparecía como miembro de la comunidad moderna e industrial de las grandes potencias. ${ }^{27}$ El imperialismo japonés estaba interrelacionado con otros dos movimientos en Japón: uno, el que promovía la expansión pacífica y el otro, el panasianismo, que conside- raba a Asia como una sola, en la cual Japón debía desempeñar el papel principal para guiar a los asiáticos, la ley y el orden de un estado moderno.

En 1900 Japón participó en la expedición internacional a China para luchar contra los bóxers. Japón protegía así los intereses occidentales enviando 10000 tropas, equivalente a las tropas extranjeras participantes. Japón fue invitado a la conferencia de paz y se hacía por primera vez presente en una conferencia internacional. Japón se convirtió en una de las potencias firmantes del Protocolo Bóxer y obtuvo el derecho de tener tropas en Tientsin y Pekín. En 1902 Japón firmó una alianza con los ingleses que reconocieron a Japón el status de un poder mayor, habiéndose establecido como un factor clave en la política mundial.

Después seguiría la guerra con Rusia, que tenía intereses en Manchuria y en Corea. Japón fue nuevamente vencedor, y en la conferencia de paz en Portsmouth, N. Hampshire, obtuvo el sur de la isla Sakalin y casi todos los privilegios que los rusos tenían en Manchuria, incluyendo los puertos de Kairen y el puerto de Darien (llamado también Arthur). Corea se convirtió en un protectorado japonés.

En 1905 Japón surgió como la potencia mayor de Asia. Éste era el momento de gloria que los japoneses habían logrado desde la humillación de 50 años antes. Entre 1910 y 1912 Corea fue anexada formalmente como colonia japonesa, se renovó la alianza con Inglaterra y se firmaron tratados comerciales con Estados Unidos y Gran Bretaña que le otorgaron la autonomía tarifaria.

\section{Conclusiones}

Debe reconocerse que durante los primeros 25 años de invasión extranjera, la política tanto en China como en Japón no diferían mucho. A ambos les fueron impuestos los tratados desiguales. Sin embargo, China estaba en el centro de esa política, mientras que Japón se encontraba en la periferia de los intereses ingleses, el poder dominante en la 
zona. En esa etapa, el sistema de puertos abiertos aplicado a China y Japón reflejaba la mayor importancia otorgada por los occidentales al comercio, mientras los japoneses y chinos se preocupaban más por las consecuencias políticas. Por ello, hacían concesiones económicas sin pensarlo. ${ }^{28}$

La "apertura forzada" de China y Japón en el siglo XIX se dio en un contexto de expansión imperialista de occidente, llevada a cabo por estados modernos e industrializados. Los líderes de Meiji, a diferencia del gobierno imperial Qing, supieron reconocer esto y establecieron como prioridad de su política convertir a Japón en un estado moderno. Esto no impidió que en los inicios de la Restauración se reconociera la inferioridad japonesa con respecto a occidente en materia militar y de industrialización. Por tanto, en el corto plazo fueron aceptados los tratados, mientras Japón iba industrializándose y aplicando una política expansionista en Asia. Para ello se requería del apoyo popular y los líderes de Meiji lograron unificar al pueblo en torno a esa política expansionista. Es decir, el gobierno centralizado de Meiji supo reconocer el vínculo estrecho entre la política externa e interna y no descuidó la primera.

La transformación de Japón en una potencia militar fuerte recibió todo el apoyo del gobierno central. En China, por el contrario, el gobierno más preocupado por la política interna, no supo reconocer ese vínculo tan importante entre lo interno y lo externo; por lo tanto careció de una política de relaciones exteriores coherente. Tampoco, y a diferencia de Meiji, los modernizadores chinos, ubicados en la periferia, recibieron el respaldo de una política consistente de apertura. La "China marítima" fue dejada a su suerte y el poder occidental aprovechó ese resquicio para incrustarse en el continente.

Así, la China imperial, que se había considerado por dos mil años "el país del centro del mundo", llegó al siglo XX inmersa en el descontento social y con su territorio dividido entre los poderes occidentales y Japón, el cual había logrado sacudirse el yugo extranjero y ahora era considerado por la comunidad internacional, como un estado moderno y soberano. Los líderes de Meiji lograron entender a tiempo la amenaza que constituía el poder occidental y que la única forma de expulsarlo era "aprendiendo el modo de hacer las cosas como los países desarrollados de occidente". Su objetivo: volverse una nación poderosa industrial y militarmente. En la primera década del siglo XX Japón se había convertido en una potencia imperialista, con colonias en Asia.

\section{Notas}

1 Agradezco al profesor Omar Martínez Legorreta, investigador del Colegio Mexiquense, sus valiosos comentarios en la revisión de este artículo.

2 Citado en William Nester. American Power, the New World Order and the Japanese Challenge. Macmillan Press, Ltd., 1993, p. 111.

3 Así lo manifestó Mao Tse Tung en su discurso de Tiananmen: "China at Fifty. Can China change?", The Economist, 2 de octubre de 1999, p. 33.

4 La globalización actual no es un fenómeno nuevo, ya el mundo había experimentado otras etapas con características similares. Precisamente, las cinco décadas que terminan con la primera guerra mundial fueron un período de intenso flujo de bienes, capital y personas. Tres diferencias sobresalen entre la globalización del siglo XIX y la actual: en la primera, grandes regiones del mundo quedaron excluidas de ese proceso, ahora la mayoría de las economías se han abierto (incluidas Latinoamérica y Asia); la segunda fue impulsada por la baja en los costos de transporte y la actual por la baja en los costos de comunicación; tercera, los flujos financieros son mucho mayores ahora. Además, el entorno político en ambas épocas es diferente. Véase Edward Mansfield. "The New Wave of Regionalism”, en International Organization, vol. 53, núm. 3, verano de 1999, pp. 589-629; también The Economist, "Thinking about globalisation: Popular Myths and Ecomic Facts", diciembre de 1997.

5 Mansfield, op. cit., pp. 596-597.

6 Wang Gungwu. "Long Path to Power", en Far Eastern Economic Review, 10 de junio de 1999, pp. 40-44.

7 W. G. Beasley. "The foreign threat and the opening of the ports", en The Cambridge History of Japan, vol. 5, cap. 4,1989 , p. 259.

8 La cláusula de Nación Más Favorecida significa, aún hoy día, que el beneficio en comercio otorgado por un país a otro, será también disfrutado por los otros países con los que el otorgante tiene relaciones de comercio.

9 John King Fairbank. China, una nueva historia. Chile: Ed. Andrés Bello, 1996, pp. 231-239.

10 Las ideas de Hume (Political Discourses, 1752), Smith (The Wealth of Nations, 1776) y Ricardo (1772-1823, 
The principles of Political Economy and Taxation de 1817) apoyaban el libre comercio con una mínima interferencia del Estado, la política del laissez faire, en contraposición a las ideas proteccionistas de los mercantilistas de los siglos anteriores. Véase Dennis Appleyard y Alfred Field.International Economics. Tercera edición, McGraw Hill, 1998, caps. 2-3.

11 Fairbank, op. cit., p. 246.

12 Beasley, op. cit., p. 260.

13 Fairbank, op. cit., p. 263.

14 Fairbank, op. cit., cap. 11, p. 266.

15 Jonathan Spence, "Paradise lost", en Far Estern Review, vol. 162, núm 15, April 15, 1999, pp. 45-46.

16 Esta clasificación es de acuerdo con Kaibara Yukio, Historia del Japón. México: Fondo de Cultura Económica, 2000, cap. 27, p. 176.

17 Algunas fuentes que analizan el desarrollo de Japón son Thomas Smith, Native Sources of Japanese Industrialization, University of California Press, 1988. Penelope Francks, Japanese Economic Development, Theory and Practice, Routledge, Gran Bretaña, 1993. Masahide Bito y Akio Watanabe.Esbozo cronológico de la historia del Japón. Japón: International Society for Educational Information, 1985.

18 Marius Jansen. "The Meiji Restoration", en The Cambridge History of Japan, vol. 5, Cambridge University Press, 1989, cap. 5, p. 338. Beasley, op. cit., p. 280.

19 Sydney Crawcour. "Economic change in the nineteenth century", en The Cambridge History of Japan, vol. 5, Cambridge University Press, 1989, cap. 9, p. 600. Jansen, op. cit., p. 341.

20 Beasley, op. cit., p. 303.

21 K. M. Panikkar.Asia y la dominación occidental.Eudeba, 1965, p. 364.

22 Citado por Akira Iriye. "Japan's drive to great-power status", en Marius Jansen (ed.) The Cambridge History of Japan. Cambridge University Press, 1989, vol. 5, cap. 12, p. 734 .

23 Iriye, op. cit., p. 735.

24 Citado en Pannikkar, op. cit., p. 369.

25 Iriye, op. cit., p. 754.

26 Crawcour, op. cit., p. 609.

27 Iriye, op. cit., p. 771.

28 Beasley, op. cit., p. 301. Ty:- 